\title{
Historia ¿para qué?
}

\author{
History, whatever for?
}

\author{
Martha Díaz Gómez*
}

Es el título de un libro editado en 1980, en el que un grupo de escritores e historiadores de la época responden a la pregunta ¿para qué sirve la historia? formulada por las autoridades del Archivo General de la Nación. El libro, con las respuestas a manera de una serie de ensayos integrados en un solo texto, fue publicado para fundamentar la necesidad de preservar los archivos históricos de la nación en el edificio que por muchos años había albergado la cárcel de Lecumberri. El inmueble fue acondicionado para recibir a la gran cantidad de toneladas de documentos que integran la memoria de nuestro país y que son la base fundamental para la reconstrucción, análisis y difusión de nuestra historia.

En los 10 ensayos que contiene el libro, los autores abarcan diferentes aspectos, visiones y enfoques sobre la utilidad, legitimidad y necesidad de la historia. Luis Villoro expresa en su texto titulado «El sentido de la historia» que la primera respuesta que acude a la mente es: "La historia obedece a un interés general del conocimiento, porque cumple con una función, la de ayudarnos a comprender el presente... parecería que, de no remitirnos a un pasado con el cual conectar nuestro presente, éste resultara incomprensible, gratuito y sin sentido. " En el ensayo «Historia, ¿para qué?» Carlos Pereyra, el autor, señala que «quienes participan en la historia que hoy se hace, están colocados en mejor perspectiva para intervenir en su época cuanto mayor es la comprensión de su origen».

Estos conceptos son perfectamente aplicables a la odontología, que se entiende con mayor claridad cuando se conoce su origen y desarrollo. En las últimas décadas ha aumentado el interés por la historia de la odontología en nuestro país, y cada vez más instituciones la incluyen en sus planes de estudios. En la Facultad de Odontología de la UNAM se ha impartido desde hace más de 30 años, en ocasiones como una materia optativa, y últimamente como un seminario que se ubica en el décimo semestre de la licenciatura. La creación del Departamento de Historia y de la Sala de la Odontología Mexicana ha sido fundamental para establecer un diálogo permanente con nuestro pasado. Con el estudio de esta disciplina se incorporan las humanidades al ejercicio profesional del cirujano dentista, aportándole a éste una riqueza indiscutible.

El 18 de febrero del año en curso se cristalizó el proyecto conjunto de la Facultad de Odontología con dos facultades de la UNAM, crear un Diplomado de Historia de la Odontología, que es el primero en su género en nuestro país.

El diplomado «Historia de la Odontología, sus aspectos filosóficos, éticos y visión prospectiva», con duración de 120 horas impartidas en 30 sesiones, consta de cinco módulos, los dos primeros impartidos por profesores de la Facultad de Filosofía y Letras, el tercero por el Departamento de Historia de la Facultad de Medicina y los dos últimos por especialistas en temas de historia de la odontología, casi todos profesores de la FO. El diplomado está dirigido a cirujanos dentistas, médicos, historiadores y en general a personas con licenciatura interesadas en el tema. Al término del diplomado, el asistente tendrá una visión panorámica de los tratamientos dentales realizados en la antigüedad, del nacimiento y profesionalización de la odontología y de las razones y circunstancias por las que se desprende del ejercicio de la medicina para tomar una vida propia y sus relaciones con las ciencias de la salud.

Es de gran trascendencia para nuestra institución, por medio de este diplomado, construir puentes de comunicación y fortalecer los lazos académicos con las

\footnotetext{
* Departamento de Historia. Facultad de Odontología, UNAM.
}

Este artículo puede ser consultado en versión completa en http://www.medigraphic.com/facultadodontologiaunam 
Facultades de Filosofía y Letras, corazón de la UNAM, y con la de Medicina, con la que tanto se relaciona nuestra carrera. Los frutos no se dejarán esperar.

A la pregunta inicial de: ¿para qué le sirve la historia a un cirujano dentista?, se puede responder con una frase: nos sirve para entender mejor quiénes somos, nos sirve para ser mejores cirujanos dentistas.

Dirección para correspondencia:
C.D. Martha Díaz Gómez

E-mail: diazkuri@prodigy.net.mx 